\title{
Acciones institucionales y vinculares que favorecen la permanencia escolar de alumnos de sectores socioeconómicos desfavorecidos*
}

\author{
Institutional and relational actions that favor school retention of students \\ from disadvantaged socio-economic sectors \\ Ações institucionais e vinculadas que favorecem a permanência escolar \\ de estudantes de setores socioeconômicos desfavorecidos
}

\author{
Natalia Rosli, Paula Carlino. ${ }^{a}$ \\ a Consejo Nacional de Investigaciones Científicas y Técnicas /Universidad de Buenos Aires, Argentina. \\ Fono: 54-11-2054-5240. Correos electrónicos: nrosli85@gmail.com, paulacarlino@yahoo.com
}

\begin{abstract}
RESUMEN
Cualquier acción pedagógica que quiera impulsarse requiere una condición inicial: la permanencia escolar. En este artículo, identificamos las acciones que llevan a cabo directivos y docentes de una escuela secundaria argentina para asegurar la permanencia de estudiantes de sectores socioeconómicos desfavorecidos, con riesgo de abandono. A partir de entrevistas, observaciones de clase y documentos, caracterizamos iniciativas institucionales y de tipo vincular que han sido identificadas tanto por la bibliografía como por los actores implicados como favorecedoras de la asistencia a clase. Quienes desarrollan esta red de acciones reconocen la situación social de los alumnos, y adoptan una postura crítica a nivel político que se trasluce en su práctica educativa. Garantizada la permanencia, será necesario sortear otro desafío ineludible que incumbe a la función de la escuela: pensar cómo construir condiciones didácticas adecuadas para enseñar contenidos disciplinares.
\end{abstract}

Palabras clave: permanencia escolar, acciones, sectores socioeconómicos desfavorecidos.

\begin{abstract}
Any pedagogical action that wants to be promoted requires an initial condition: school retention. In this paper, we identify the actions done by managers and teachers from an argentine secondary school to ensure the permanence of students from disadvantaged socio-economic sectors at risk of dropping. From interviews, classroom observations, and documents, we characterize institutional and relational initiatives that have been identified both in the literature and by interviewees as favoring class attendance. Those who develop this network of actions recognize the social situation of students and take a critical stance on a political level that is shown through their educational practice. With permanence guaranteed, it will be necessary to overcome another challenge that falls on the school function: thinking how to build appropriate didactic conditions for teaching disciplinary content.
\end{abstract}

Key words: school retention, actions, disadvantaged socio-economic sectors.

Este trabajo forma parte de la tesis doctoral de Natalia Rosli, dirigida por Paula Carlino. Se enmarca en el proyecto PICT 2010-0893, financiado por la Agencia Nacional de Promoción Científica y Tecnológica (Ministerio de Ciencia, Tecnología e Innovación Productiva, Argentina). Ambas autoras están afiliadas al CONICET (Consejo Nacional de Investigaciones Científicas y Técnicas) e integran el GICEOLEM (https://sites.google.com/site/giceolem2010/) en el Instituto de Lingüística de la Universidad de Buenos Aires. 


\section{RESUMO}

Qualquer ação pedagógica que se queira impulsionar requer uma condição inicial: a permanência escolar. Neste artigo, identificamos as ações realizadas pelos gestores e professores de uma escola secundária da Argentina para garantir a permanência de estudantes de setores socioeconômicos desfavorecidos e em risco de abandono. A partir de entrevistas, observações em sala de aula e documentos, caracterizam-se iniciativas institucionais e vinculadas que foram identificadas tanto na literatura como pelos envolvidos na assistência à classe. Quem desenvolve esta rede de ações reconhece a situação social dos estudantes e adota uma postura crítica, em nível político, que transparece em sua prática educativa. Com a permanência garantida, será necessário eleger outro desafio inevitável que incumbe à função da escola: pensar em como construir condições didáticas adequadas para ensinar os conteúdos disciplinares.

Palavras chave: permanência escolar, ações, setores socioeconômicos desfavorecidos.

\section{INTRODUCCIÓN}

Usualmente, las investigaciones que abordan escuelas secundarias a las que asisten jóvenes provenientes de sectores socioeconómicos desfavorecidos ponen el acento principal en la permanencia. Siguiendo a Dabenigno, Larripa, Austral, Tissera y Goldenstein Jalif, entendemos esta noción como "el entramado de relaciones y prácticas que se despliegan en el nivel de las instituciones educativas [...] para promover que todos los estudiantes logren transitar y completar su carrera escolar, evitando el abandono" (2010: 7).

La importancia de focalizar tal aspecto reside en que cualquier acción pedagógica que quiera impulsarse requiere como punto de partida que los alumnos asistan a la escuela. Por lo tanto, es una condición inicial y necesaria que debe considerarse, especialmente en poblaciones de bajos recursos que exhiben alto ausentismo (Krichesky y Duque, 2008; Krichesky et al., 2008; Jacinto y Terigi, 2007), fenómeno que suele preceder al abandono escolar. Asimismo, faltar reiteradamente a clases equivale a disponer de menor tiempo didáctico, lo que obstaculiza la progresión de la enseñanza de contenidos y repercute, inevitablemente, en las oportunidades de aprendizaje.

Por este motivo, los aprendizajes de calidad que busca lograr la educación formal necesitan una previa reflexión acerca de cómo favorecer que estos alumnos puedan permanecer en el aula, a pesar de las dificultades sociales, políticas y económicas que presentan sus condiciones de vida. Sólo asegurando esta condición será posible pensar luego, desde áreas disciplinares en particular, intervenciones didácticas que potencien el aprendizaje de contenidos.

La mayoría de los estudios que abordan rasgos, iniciativas o estrategias escolares que favorecen la permanencia y promueven logros de aprendizaje lo hacen basándose en entrevistas a directivos, docentes y/o alumnos (Dabenigno et al., 2010; Acosta, 2009, 2006; Tiramonti et al., 2007; Feijoo y Corbetta, 2004; Cantero, 1999, entre otros). Al centrarse en estas perspectivas, suelen omitir el análisis de lo que ocurre propiamente al interior de las aulas, aun cuando aducen haber realizado observaciones de clases.

En el presente artículo, distinguimos algunas de las acciones que llevan a cabo directivos y docentes de una escuela secundaria argentina para propiciar la permanencia escolar de sus estudiantes. Para ello, nos valemos de datos provenientes de diversas fuentes de información, entre las que incluimos observaciones sistemáticas de clases. De esta triangulación de fuentes, identificamos acciones de tipo institucional y de tipo vincular como favorecedoras de la asistencia a clase. Entre las primeras, reconocemos la asunción de un compromiso con un proyecto pedagógico inclusivo, y el impulso de un trabajo colectivo 
para abordar las problemáticas que ponen en jaque la permanencia pretendida. Como acciones vinculares, registramos la construcción de un vínculo afectivo con los estudiantes, y la manifestación de confianza en su capacidad de aprendizaje. Esto aparece destacado por los actores implicados y, a la vez, es coincidente con lo señalado en la bibliografía.

Pese a su significatividad, estas acciones no aseguran un éxito total en la tarea de lograr que los jóvenes permanezcan escolarizados. Dado que los factores que intervienen en ello son múltiples y complejos, en ocasiones el desgranamiento igualmente acontece, por lo que sigue siendo uno de los mayores problemas durante la escolaridad secundaria. No puede obviarse que el desafío de generar condiciones para la inclusión educativa trasciende el plano meramente institucional, y corresponde a un conjunto de políticas sociales (Dabenigno et al., 2010; López, 2006) en las que debe incluirse el financiamiento, la infraestructura, la capacitación de profesores, etc.

A continuación, exponemos la metodología cualitativa desarrollada en estainvestigación. En los siguientes apartados detallamos las acciones institucionales y vinculares anticipadas y, finalmente, concluimos sintetizándolas y problematizando su alcance.

\section{METODOLOGÍA}

Los datos de este estudio de caso (Stake, 2000) provienen de una investigación cualitativa desarrollada en una escuela pública que se sitúa en la Ciudad de Buenos Aires. Un $60 \%$ de sus alumnos proviene de un asentamiento precario en el que habitan familias en situación de vulnerabilidad social, que denominamos "El Barrio"1. Este conjunto de estudiantes presenta problemáticas de sobreedad, repitencia, pobreza, marginación, adicciones y situaciones de judicialización. En particular, el curso de quinto año (último de la educación secundaria) en el que se condujo la indagación está compuesto por catorce alumnos: once mujeres y tres varones de entre 17 y 22 años. En su mayoría, desarrollaron trayectorias escolares discontinuas por repitencias y abandonos. Además, poseen otras responsabilidades domésticas y laborales: siete alumnos trabajan en actividades precarizadas y cinco son padres o madres de niños pequeños. Estas circunstancias reducen su tiempo disponible y ocasionan dificultades para que puedan estudiar y cumplimentar las tareas escolares en sus hogares.

El caso fue elegido porque supimos por terceros que la escuela desarrollaba un proyecto pedagógico inclusivo. Nuestro interés era observar qué ocurría en este contexto con la lectura y la escritura en materias de las ciencias sociales. A través de una fase piloto, establecimos relación con la escuela, y seleccionamos indagar el quinto año porque era donde notamos que podíamos focalizar mejor lo que nos interesaba estudiar. Si bien en este trabajo analizamos datos relativos a cómo se favorece la permanencia de los alumnos en la escuela, tenemos en curso un análisis didáctico donde nos preguntamos de qué modos se trabaja en las clases con la lectura y la escritura para aprender contenidos disciplinares.

Durante el lapso de siete meses, observamos y audiograbamos clases en tres asignaturas, entrevistamos a sus actores y recogimos documentos institucionales. Realizamos en total 39 observaciones en las asignaturas de Geografía Económica, Estudios Sociales Argentinos y Legislación Fiscal, las que, en adelante, nombramos como Asignaturas 1, 2 y 3, respectiva-

A fin de preservar la confidencialidad y el anonimato de los datos, se optó por el uso de esta denominación genérica. 
Estudios Pedagógicos XLI, N 1: 257-274, 2015

ACCIONES INSTITUCIONALES Y VINCULARES QUE FAVORECEN LA PERMANENCIA ESCOLAR DE ALUMNOS DE SECTORES SOCIOECONÓMICOS DESFAVORECIDOS

mente. Esto arroja un total de 34:38 $\mathrm{hrs}^{2}$ de audio registrado. A ello se suman once entrevistas: tres a los docentes, siete a los estudiantes del curso y una al directivo de la institución. Los audios de las entrevistas y observaciones fueron transcriptos y el conjunto de los materiales fueron analizados mediante estrategias de categorización (Maxwell \& Miller, 2008; Coffey \& Atkinson, 1996).

\section{ACCIONES DE CARÁCTER INSTITUCIONAL}

Diversos estudios destacan que ciertos estilos de gestión resultan un factor fundamental para posibilitar la permanencia escolar de adolescentes provenientes de sectores socioeconómicos desfavorecidos (Jacinto y Terigi, 2007). Estos estilos se diferencian de los modelos normativos tradicionales, que no toman en cuenta las particularidades del contexto en el que se insertan. En contraste, los integrantes de instituciones que los adoptan revelan un alto grado de conocimiento de su comunidad de referencia, y aceptan que las problemáticas sociales se imponen como cuestiones centrales a ser trabajadas porque condicionan las prácticas pedagógicas.

Reconocemos en esta escuela las acciones que concuerdan con las características institucionales enunciadas. Éstas son asumir un compromiso político con un proyecto pedagógico inclusivo y encarar un trabajo colectivo para abordar problemáticas.

\subsection{ASUMIR UN COMPROMISO CON UN PROYECTO PEDAGÓGICO INCLUSIVO}

Uno de los rasgos identificados como favorecedores de logros pedagógicos en alumnos de sectores populares es la dimensión ética de los proyectos y las acciones de las instituciones educativas (Cantero, 1999). Ésta abarca, entre otros aspectos, el compromiso de los integrantes de la escuela por efectuar una acción educativa que resulte transformadora para estos estudiantes. Según Acosta (2006), este compromiso representa una condición para sostener el trabajo en estas instituciones.

En esta escuela identificamos, tanto en el discurso como en las acciones, un compromiso del directivo y de los docentes entrevistados en pos del cumplimiento del proyecto pedagógico planteado. De acuerdo con uno de los documentos institucionales recogidos, nombrado Proyecto Escuela, como objetivo principal se pauta "la permanencia y el aprendizaje de calidad".

En vías de facilitar la consecución de estos fines, la escuela promovió durante años un espacio de reunión entre los docentes en el que se debatían los principios ético-políticos que dieron origen al proyecto - provenientes de autores latinoamericanos como Paulo Freire y Antonio Gomes Da Costa-, a la vez que se vinculaban con situaciones efectivamente ocurridas en el aula. Según Fernández (1994), estos ámbitos formativos y de encuentro que promueven la reflexión, favorecen el sentimiento de pertenencia institucional del cuerpo docente. Los tres profesores indagados en nuestro estudio mencionaron haber participado en algún momento de estas reuniones voluntarias que encabezaba el rector los días sábados.

Estos objetivos descritos en el Proyecto Escuela también aparecen condensados en el discurso del directivo y los docentes entrevistados. A continuación transcribimos algunas

El total de horas observadas se calculó a partir de la duración real de los audios. 
de sus expresiones que lo denotan:

[...] usamos términos como "la inclusión", "contra la exclusión" [...] no es solamente a favor de la inclusión sino es emancipadora [...] El eje [del proyecto pedagógico] estaba puesto en, primero, que los chicos tengan escuela. No se puede educar si no están los chicos en la escuela. Dentro de la escuela habrá que pensar [...] las perspectivas culturales, sociales, los modos de vida [...] “Cómo hago para que se quede?” [...] A nosotros nos interesan los chicos [...] Tienen que estar en la escuela [...] Le decimos "tenés que quedarte" [...] (Entrevista al rector de la institución).

En la cita anterior, el directivo enuncia la permanencia escolar como eje fundamental que la institución adopta como política. Es por ello que, según relata, el principal interrogante que se formula es cómo hacerla efectiva. La referencia a términos como "inclusión", "emancipadora" coincide con los conceptos utilizados en los documentos institucionales que explicitan el proyecto pedagógico.

Según el entrevistado, esta búsqueda de inclusión debe ser encarada a partir del reconocimiento del sentido político de la tarea docente: la capacidad de transformar el destino de los alumnos. Tal como lo enuncia en otra parte de la entrevista, este principio orienta las acciones pedagógicas más allá de lo estrictamente técnico.

[...] uno tiene en este lugar social, un lugar político [...] Sos una persona cuyo quehacer o no hacer tiene que ver con el destino de una comunidad. [...] Lo más importante de tu trabajo es lo conceptual, no lo técnico. Por eso digo que, en realidad, un buen docente es el que descubrió el sentido de su tarea [...] (Entrevista al rector de la institución).

Al igual que las afirmaciones del rector, las acciones y el discurso de los docentes participantes de la investigación también muestran el compromiso que han contraído. Durante el tiempo que lleva trabajando en la escuela, el profesor de la Asignatura 1 fue docente en todos los años de la escuela y también secretario. En la entrevista relató que este recorrido le permitió vivenciar los comienzos de la institución, involucrándose en la organización de diversas reuniones e interactuando recurrentemente con los vecinos de "El Barrio" en el que habita la mayoría de los alumnos matriculados en la escuela.

Por su parte, el docente de la Asignatura 2, quien dictaba clases en años inferiores, volvió a escoger desempeñarse en la escuela al tomar un cargo disponible en quinto año. Según relató, dicho puesto había permanecido vacante durante dos meses ya que ningún profesor externo lo había aceptado debido al estigma de marginalidad que allí recae sobre los alumnos. De modo similar, la profesora de la Asignatura 3 ingresó a la escuela tras tomar un cargo para el cual los directivos no conseguían docente desde hacía tiempo. Ambos integran proyectos de apoyo escolar y terminalidad secundaria que se llevan a cabo en la institución, y que ofrecen ayudas pedagógicas para favorecer la inclusión educativa.

Las actividades que realizan estos tres docentes revelan una elección personal por trabajar en esta institución y formar parte de su proyecto pedagógico inclusivo. En este punto se diferencian de los profesores que comúnmente ingresan a escuelas que atienden a estos sectores, que lo hacen como puerta de entrada a la docencia (UNESCO/IIPE, 2000), pero enseñan allí sin un deseo que lo sostenga (Foglino, Falconi y López Molina, 2008). Al mismo tiempo, contrastan con la tradicional "actitud de huida" de las instituciones que atienden a población en riesgo, verificada en otros profesores (Cantero, 1999). 
Estudios Pedagógicos XLI, Nº 1: 257-274, 2015

ACCIONES INSTITUCIONALES Y VINCULARES QUE FAVORECEN LA PERMANENCIA ESCOLAR DE ALUMNOS

DE SECTORES SOCIOECONÓMICOS DESFAVORECIDOS

De igual forma, en las entrevistas se advierte el compromiso que han asumido con este proyecto pedagógico.

[...] vos si en esta escuela "te pusiste la camiseta" [te identificaste con su ideario] [...] no te vas más [...] los profes [profesores] que logran entender, internalizar, los que logran querer a los pibes [jóvenes] [...] están contribuyendo [...] a cambiar la realidad. [...] Hablás de los pilares que fundan esa escuela [...] qué plus le pones a la tarea que vos estás haciendo. [...] Plus en términos politicos. [...] Son pibes que merecen doblemente la posibilidad de poder pensar [...] Entonces el hecho de uno entender y comprometerte con ese proyecto [...], pertenecer a un proyecto que intenta mejorar la vida [...] (Entrevista al profesor de la Asignatura 1).

[...] el otro día que fui [a clase] también me dijo uno de los chicos "[...] voy a dejar la escuela porque tengo que trabajar [...]". Y yo le decía que [...] ellos tienen que venir y estudiar [...] porque estudiar es un derecho [...] Cuando habló conmigo yo le dije que no, que hay que replantear, buscar algún trabajo part-time [...] "No, voy a seguir" me dijo después [...] (Entrevista al profesor de la Asignatura 2).

[...] Hay que ser realistas, yo me tengo que poner en la piel del pibe [ser empática con el joven]. ¿Yo qué le puedo decir a Martín [alumno de quinto año] hoy cuando me tira [dice] "tengo problemas que me agobian"? [...] ¿Qué le puedo decir? "A ver, explícame lo de Seguridad Social”. Bueno, hoy no me lo podés explicar, tenemos tiempo, me lo explicas más adelante. (Entrevista a la profesora de la Asignatura 3).

En los fragmentos de entrevistas citados se evidencia una mayor apropiación de los conceptos del proyecto pedagógico en el docente de la Asignatura 1, con mayor antigüedad en la escuela. Éste menciona la importancia de añadir un "plus político" al sentirse parte del proyecto escolar y encarar la tarea docente, comprendiendo que la escuela puede "cambiar la realidad" de estos alumnos. El profesor de la Asignatura 2 da cuenta de su compromiso por la inclusión escolar, a través de un ejemplo en el que se vislumbra su defensa del derecho a la educación de estos jóvenes. Por su parte, la docente de la Asignatura 3 denota en el fragmento de entrevista citado su adhesión al proyecto educativo, al comprender las problemáticas de un alumno y permitirle que cumplimente en otro momento las actividades áulicas requeridas.

En síntesis, documentos institucionales y entrevistas con el rector y profesores de la escuela manifiestan un ideario común que considera como parte de la labor docente asegurar la permanencia de los alumnos en la escuela al contemplar sus necesidades. Esta identificación con los valores de un proyecto político pareciera no sólo orientar, sino sostener la labor de los profesores.

\subsection{ENCARAR UN TRABAJO COLECTIVO PARA ABORDAR PROBLEMÁTICAS}

Existe una profusa bibliografía sobre gestión educativa que destaca el trabajo en equipo en las escuelas (Acosta, 2006), debido a que éste impulsa las acciones institucionales hacia objetivos comunes (Redondo, 2004). De acuerdo con Dabenigno et al. (2010) y Jacinto y Freytes Frey (2004), las escuelas que obtienen buenos resultados para retener a sus alumnos cuentan con un grupo motor de integrantes involucrados en el logro de ese fin. Este abordaje conjunto se diferencia de las formas de trabajo individual que Belossi y Palacios de Caprio (1999) hallaron en forma predominante en escuelas que reciben población de sectores sociales desfavorecidos. 
La consolidación de un grupo de trabajo para afrontar las problemáticas emergentes desde los lineamientos planteados en el proyecto pedagógico permite sostener el compromiso asumido. Los actores que entrevistamos refieren que en esta escuela las problemáticas que ponen en cuestión la permanencia escolar pretendida se analizan y se discuten con otros miembros de la institución. Ante alguna situación que obstaculice su labor, los profesores pueden recurrir a tutores, preceptores, colegas, asesores pedagógicos o directivos para pensar estrategias de abordaje. Asimismo, estos últimos pueden acudir al plantel docente cuando entienden que no pueden manejar solos alguna cuestión.

El modo de funcionamiento de este trabajo en equipo fue descrito detalladamente por el rector de la institución en la entrevista realizada.

[...] el acompañamiento a ese profesor, no dejarlo solo: hay un preceptor que está con él [...] Yo les decía [a los docentes] siempre "Ustedes no consideren que el problema que tienen con un alumno es un problema de ustedes [...]; [por el contrario,] es un problema de la escuela". Por lo cual un profesor nunca tiene que ir a abordar solo ese problema. [...] No tiene que ser un problema tuyo, tiene que ser un problema del equipo, un problema colectivo, una respuesta colectiva [...]. Como trabajamos en equipos, uno permanentemente [tiene] al profesor, al preceptor, al coordinador, al asesor pedagógico [...]. (Entrevista al rector de la institución).

En la cita anterior, este directivo destaca el acompañamiento que se ejerce ante alguna dificultad con la que un docente pueda toparse. Ante ello, resalta la necesidad de afrontarla como un "problema colectivo" y, a partir de allí, buscar una solución conjunta. Esto contrasta con el habitual aislamiento profesional que impide que los docentes discutan su tarea (Poggi, 2003), aprendan de las dificultades y conviertan los obstáculos en desafíos a ser problematizados. Los siguientes fragmentos de entrevista con los profesores ejemplifican esta forma de trabajo.

[...] hay pibitos que están de fierro [portan armas] todos los días. [Hacer frente a esto] es un abordaje que es común de todo el cuerpo docente. Es un abordaje institucional [...] (Entrevista al profesor de la Asignatura 1).

[...] Veo que no hay [...] el código del respeto del adulto [...] todo un tema con respecto a las malas palabras [insultos] ahí. $Y$ acá bueno, lo dicen abiertamente y a veces uno no tiene que reaccionar, eso es lo que el otro día hablábamos con Paulina ${ }^{3}$ [rectora actual de la escuela]. Porque ellos tienen otra realidad, vienen mal, vienen drogados [...] A los que les fue bien [en los exámenes de su materia] los felicito [...] Eso lo aprendí de Mauricio [ex rector] [...] cuando empecé acá [...], que tenía dificultad con un alumno [...]: marcar lo que tiene que mejorar y marcarle lo otro, porque [...] lo incentiva a que logre lo que está fallando [...] (Entrevista al profesor de la Asignatura 2).

[...] Acá hay un docente tutor, que acá [quinto año] es Carmen y por ahí ella lleva a la reunión de tutoría los comentarios, conflictos [...] de los distintos docentes [...] Por otro lado, tenés el asesor pedagógico [...] le podés pedir ayuda a él [...] y si no, con la Dirección se puede hablar tranquilamente de un montón de cuestiones [...] A mí cuando me pasó lo del examen que a todo el mundo le fue mal [se refiere a un parcial escrito en el que sólo aprobaron tres alumnos], le dije al asesor "Che, me pasó esto, ¿qué hacemos?”. Y después se lo dije a Paulina [...] (Entrevista a la profesora de la Asignatura 3).

Los nombres propios que se incluyen a lo largo de este artículo son seudónimos que preservan la identidad de los entrevistados. 
En las citas previas, el docente de la Asignatura 1, al mencionar la delincuencia como problemática que presentan algunos alumnos, refiere al abordaje institucional que se encara. Los profesores de las Asignaturas 2 y 3 relatan situaciones en las que acercaron sus inquietudes a otros integrantes de la escuela. El primero interpeló a los directivos por su incomodidad ante los insultos de sus alumnos y por una dificultad específica con uno de ellos, mientras que la segunda lo hizo por las bajas calificaciones que obtuvieron en su examen. Estos ejemplos dan cuenta de una reflexión conjunta con otros actores institucionales acerca de cómo hacer frente a sus preocupaciones. Efectivamente, a partir de estas consultas, decidieron no reaccionar ante las agresiones verbales de los estudiantes, referirse a lo positivo en su desempeño escolar y cuestionarse el porqué de los resultados en la evaluación administrada.

Este abordaje colectivo de problemáticas pudo ser observado durante nuestro trabajo de campo. Registramos en el cuaderno de notas una reunión entre docentes y directivos en la sala de profesores, en la que se debatió en forma conjunta qué decisión tomar ante el descubrimiento de que un grupo de alumnos había fumado marihuana en un aula durante el recreo.

Estos ejemplos dan cuenta de una decisión institucional para que los profesores de la escuela desarrollen una actitud tolerante y paciente con los alumnos que, a la vez, les permita progresivamente cuestionarse su propia injerencia en sus comportamientos. A sabiendas de la procedencia barrial de los alumnos, en la que es común que vivan episodios de violencia, estos profesores resuelven resaltar lo positivo y brindar contención, a favor de su permanencia escolar. Sólo una larga experiencia de sentirse acogido, tolerado y esperado permitirá a estos alumnos incorporar gradualmente las pautas de convivencia esperadas.

\section{ACCIONES DE CARÁCTER VINCULAR}

La dimensión vincular es una vía sustancial para poner en acción objetivos institucionales en las escuelas que atienden a estos estratos socioeconómicos desfavorecidos (Ziegler, 2011; Redondo, 2004; Belossi y Palacios de Caprio, 1999). Debido a que la mayor cantidad de tiempo escolar lo transitan frente a un profesor, una buena relación entre docentes y alumnos puede motivar a estos últimos a asistir a clase, propiciando la permanencia escolar que se pretende.

Hallamos que los actores de esta institución, en línea con el compromiso políticoideológico que asumen y el abordaje en equipo de problemáticas, desarrollan acciones que tienden a construir un vínculo afectivo con los alumnos, y a manifestar confianza en su posibilidad de aprender.

\subsection{CONSTRUIR UN VÍNCULO AFECTIVO CON LOS ALUMNOS}

Involucrarse en forma positiva con la escuela y sus integrantes es uno de los factores que contribuye al sostenimiento de la escolaridad (Fredricks, Blumenfeld \& Paris, 2004). Al respecto, Dabenigno et al. (2010) señalan que el lazo afectivo que los estudiantes establecen con sus profesores favorece su sentido de pertenencia a la institución lo que, a la vez, anima a que continúen asistiendo a clases.

En consonancia con estas perspectivas, desde los documentos institucionales se acuerda que los educadores han de encarar un proceso de vinculación interpersonal para constituirse en referentes significativos de los alumnos. Basándose en los principios de Pedagogía 
sin Violencia y Pedagogía de la Presencia, que retoman conceptos de los intelectuales latinoamericanos Paulo Freire y Antonio Gomes Da Costa, definen esa relación a través de las características que debe ofrecer el adulto: respeto, buen trato, atención de las demandas, gestos de afecto y diálogo.

Algunos de estos aspectos vinculares fueron mencionados por el rector en la entrevista como necesarios para el trabajo áulico diario:

[...] en esta escuela a los chicos se los trata bien, no se los puede tratar mal, no se puede gritar a un chico [...] nosotros somos adultos, somos educadores [...] yo esto no lo pongo en discusión: si vos no querés a los pibes, no podés [educarlos...] [A los alumnos] les importa lo que hacés vos en el aula y cómo te vinculás [...] Se dan cuenta si vos los querés o no los querés, ellos lo perciben [...] El marco tiene que ser siempre ése, como el vínculo de buen trato, buena relación, de diálogo, de poder escuchar [...] Vos podés entrar a una clase [...] "Chicos, buen día, ¿cómo andan? ¿Están bien?” [...] Te tomás algunos minutos para ver si hay alguna cuestión [...] (Entrevista al rector de la institución).

Del mismo modo, los profesores de las materias que observamos reconocen en las entrevistas el valor de este vínculo, argumentando acerca de la importancia de desarrollar una relación significativa con los alumnos o aportando ejemplos de ésta:

[...] hay un clima de trabajo que es necesario [...] Hay mucho de buen trato y de respeto que tenés que permanentemente tener [...] Estar atento a las demandas [...] [Los alumnos en quinto año] están mucho más receptivos [...] Se han encontrado con una escuela amigable, con adultos significativos [...] Los pibes entran sabiendo quién sos vos [...] Saben que no sos ortiva [traidor] [...], que no los juzgás [...] (Entrevista al profesor de la Asignatura 1).

[...] El otro día, entrevisté a un chico de primer año que lo veíamos que estaba mal, y le decíamos "Bueno, pero nosotros te queremos ayudar", "No, no, pero vos me enfermás [me enloquecés]" le decía a la preceptora. "Pero ella te está tratando bien" [...] Uno siempre tiene que estar, no ponerse al nivel de él y tampoco voy a gritar. Yo no soy de gritar. [En cambio, sí soy] de decirle "Nosotros te estamos tratando bien a vos, te queremos ayudar" [...] (Entrevista al profesor de la Asignatura 2).

[...] No concibo poder explicarle algo a un pibe y que el pibe me pueda entender si yo no tengo un vínculo establecido con él [...] Partimos del respeto, eso es básico [...] Pero es elemental construir un vínculo, y es algo que se va construyendo, eh [...] llegar, darte un beso, que te cruzás en cualquier lado, preguntar cómo está uno [...] Una palmadita en la pierna, o en el brazo, “Qué tal? ¿Cómo estás?” [...] Yo creo que a ellos les queda que hay un vínculo afectivo con la otra persona [...] (Entrevista a la profesora de la Asignatura 3).

En los extractos anteriores, puede notarse cómo los docentes de las Asignaturas 1 y 3 conceptualizan el vínculo que creen necesario establecer con los alumnos para poder dictar clases en sus materias. Ambos refieren a esa relación como algo procesual que tanto el profesor como el alumno construyen de a poco. El profesor de la Asignatura 2 hace referencia a la significatividad de los vínculos, y aporta un ejemplo en el que intervino asistiendo a un alumno alterado. 
Más allá de la importancia que atribuyen directivos y docentes a estos vínculos, para evaluar su alcance resulta necesario recabar la opinión de los estudiantes. Al respecto, distintas investigaciones han encontrado que en las escuelas que atienden a estas poblaciones de bajos recursos, los alumnos asignan gran importancia al involucramiento emocional con sus docentes (Ziegler, 2011; Dabenigno et al., 2010; Feijoo y Corbetta, 2004; Belossi y Palacios de Caprio, 1999).

Similar jerarquía otorgan los estudiantes del curso indagado a su vínculo con estos docentes. En las entrevistas -la mayoría realizada de a pares-, seis de ellos adujeron sentir a sus profesores como una fuente de contención afectiva que les brinda ayudas de diverso tipo. Mencionaron que los tres docentes participantes de esta indagación conversan con ellos, los escuchan, los aconsejan, toman en cuenta sus situaciones de vida, por lo que llegan incluso a sentirlos como familiares o amigos.

Martín: [...] te incentiva. Ves que te preguntan, “¿Y? ¿Cómo te está yendo?”, te ayudan si pueden...

Denise: [...] aparte de ser profesores, como que te ayudan, ¿entendés?

Martín: Te hablan como del lado de afuera.

Denise: Te hablan como si fuesen tus papás.

Martín: Por eso, yo hablo con Sonia [profesora de otra asignatura] y me dice “¿Y Martín? Te tenés que poner las pilas [afrontar una tarea]. Tenés que terminar" [...] Como un amigo te lo dicen. No se pone en el lugar de profesor.

Entrevistadora (en adelante, $\mathrm{E}$ ): ¿Y a vos te sirve cuando te dice así?

Martín: Sí porque se preocupa. [...] Bueno, y la profesora de Inglés sabe [que mi pareja está embarazada] y viene y me pregunta. Pero yo creo que Sonia [...] es una madre más.

(Entrevista a los alumnos Denise y Martín).

Nadia: [...] la escuela siempre ayuda, ¿entendés? Otra escuela capaz [...] tenés un problema familiar [... pero] no se meten [...] Acá es distinto, ponéle, yo hace poco cuando mi papá cayó [terminó] preso, [a] nosotros nos dieron... por si queríamos ir al psicólogo, estuvieron más atentos [...] Nosotros tenemos una confianza con profesores que sí o sí vas a tener que contarle [...] Y después mi mamá tuvo un accidente [...] Me ayudaban, venían, preguntaban si estábamos bien, que venga a la escuela, que ellos me miraban al nene [su hijo pequeño]. Yo lo traía, lo dejaba con los profesores. Lo cuidaban, si el nene lloraba, lo subían [al aula].

Lautaro: [...] Ya uno viniendo al colegio ya hacen muchísimo, te ayudan muchísimo, lo que pueden [...] [La profesora de la Asignatura 3] es una persona excelente porque podés hablar cualquier cosa con ella. [...]

Nadia: Sonia [profesora de otra materia no observada] también.

Lautaro: Claro, es más mamá Sonia, ¿entendés? [...] te acaricia, es mimosa.

(Entrevista a los alumnos Nadia y Lautaro).

Guadalupe: [...] acá en el colegio vos tenés una confianza con los profesores [...] está bueno porque es como una gran familia, ¿entendés? Todos conocen a todos, los profesores todos saben tu vida y si sos de "El Barrio", si no. Está bueno eso [...] Porque te dan ganas de venir al 
colegio [...] Son todos así. [...] Decís "Uh, bueno, tengo con Vero [profesora de la Asignatura 3] tres horas [de clase] pero bueno, no importa, voy igual" [...] Por eso te digo que es como diferente por ahí a otros colegios.

(Entrevista a la alumna Guadalupe).

Fabiana: [...] te tiran chistes ahí. O te tiran un “¿Qué onda? ¿Qué pasó en el curso?”, que José [profesor de la Asignatura 1] te pregunta qué materias seguís [...] las materias que vos querés cursar [...] o te ayudan en las previas [asignaturas que no fueron aprobadas aún, pendientes de dar nuevamente el examen]. [...] Son profesores que te ayudan mucho en todo sentido [...] Porque si no te llevás bien con el profesor..., me cuesta llevarme bien con la materia. [...] Tengo que prestarle atención al profesor. O decirle "Profe, no entiendo" y ese "no entiendo" no se lo puedo preguntar si yo estoy enojada. [...] Me costaría más la materia. [...]

(Entrevista a la alumna Fabiana).

En las citas transcriptas, los estudiantes destacan diversos aspectos presentes en el vínculo afectivo con sus docentes. Resaltan las ayudas pedagógicas, prácticas o emocionales que les ofrecen en distintas situaciones: les preguntan “¿cómo te está yendo?” (Martín), permiten que una alumna lleve a clase a su hijo pequeño mientras ellos "lo cuidaban" (Nadia) y "te ayudan en las previas" (Fabiana). Es por ello que, conociendo estos soportes que los docentes les brindan, los alumnos admiten que les tienen confianza (Nadia y Guadalupe), y asemejan sus intervenciones a las que podrían recibir de familiares (Denise, Lautaro y Guadalupe) o amigos (Martín). En especial, los últimos dos fragmentos aluden a la importancia de estos vínculos como canal para facilitar la permanencia escolar, ya que las estudiantes afirman que relacionarse de esa forma con sus profesores las incentiva a asistir a la escuela (Guadalupe), y les facilita la cursada de materias (Fabiana).

De modo más conciso, otros seis alumnos del curso hicieron referencia a este vínculo interpersonal, aunque sólo mencionaron aspectos de personalidad que les agradan de sus docentes.

Marisa: [El profesor de la Asignatura 2] Es buen profesor [... ] No te grita ni nada.

Claudia: Es buenito, es tranquilo. No como...

E: ¿Qué, hay profesores que no son tranquilos?

Claudia: No, hay [algunos] que te gritan. Y eso no me gusta. Pero él es tranquilo, te habla despacito, todo amor y paz [Risas].

(Entrevista a las alumnas Marisa y Claudia).

E: ¿Y del profesor [de la Asignatura 2] qué piensan ustedes? ¿Les gusta cómo enseña?

Carla y Lorena: Sí.

E: ¿Y todos los profesores son así?

Carla: La mayoría.

Lorena: Sí. Son macanudos [amigables].

(Entrevista a las alumnas Carla y Lorena). 
Estudios Pedagógicos XLI, N 1: 257-274, 2015

ACCIONES INSTITUCIONALES Y VINCULARES QUE FAVORECEN LA PERMANENCIA ESCOLAR DE ALUMNOS DE SECTORES SOCIOECONÓMICOS DESFAVORECIDOS

Ernesto: José [profesor de la Asignatura 1] es piola [simpático].

Ariana: Es un capo [excelente] [...] iAguante José! [iViva José!].

(Entrevista a los alumnos Ernesto y Ariana).

Con términos como "tranquilo”, "macanudo”, "piola”, “capo” y “¡Aguante José!”, estos estudiantes también expresan su valoración positiva de los docentes. Estas apreciaciones sobre la forma de ser de los profesores con los alumnos, que indican el tipo de vínculo que apuntan a construir con ellos, son el modo más común mediante el cual estos alumnos del nivel medio dan indicios de su relación con los profesores (Kessler, 2002).

En síntesis, en las entrevistas a profesores y alumnos se observa una toma de conciencia por parte de los primeros de que cierto tipo de vínculo afectivo con los segundos es una condición necesaria para llegar a ellos con su enseñanza. Estar disponible, ser receptivo, escuchar, interesarse por sus cuestiones personales, respetarlos, entender su situación, etc., son actitudes que vuelven a estos docentes confiables y respetados a los ojos de sus estudiantes. Sin ese vínculo, probablemente, los docentes no serían escuchados. Este principio podría caber para cualquier contexto educativo pero aparece en primer plano con relación a este alumnado, que exhibe historias familiares y sociales atravesadas por la exclusión, la fragmentación, la violencia, la desatención de necesidades básicas y, por ende, la falta de reconocimiento como sujetos de derecho.

\subsection{MANIFESTAR CONFIANZA EN LA POSIBILIDAD DE APRENDIZAJE DE LOS ALUMNOS}

Es sabido que las representaciones que tienen los profesores de sus alumnos inciden en su desempeño escolar (Kaplan, 2010; Bourdieu y Saint Martin, 1998). A tal punto que Rosenthal \& Jacobson (1968) afirman que concebirlos como capaces de aprender suscita su avance al modo de una profecía autocumplida. Esta apuesta por su aprendizaje resulta determinante para la relación pedagógica (Falconi, 2011; Thisted, 2011; Carlino, 2005; Bain, 2004; Cornú, 1999), y puede generar condiciones para motivar la permanencia escolar.

En concordancia con el vínculo afectivo que entablan, los integrantes de esta escuela sostienen una confianza en que los alumnos, pese a la compleja realidad socioeconómica que viven, son capaces de aprender los contenidos disciplinares que se les enseñan. Adoptando esta postura, se sitúan en el polo opuesto de los discursos fatalistas que, según Baquero (2001), sospechan sobre la "educabilidad" de los jóvenes de sectores socioeconómicos desfavorecidos, llegando a dictaminar incluso, tal como cuestionan Kaplan (2005), Frigerio (2004) y Belossi y Palacios de Caprio (1999), que inevitablemente fracasarán en la escuela.

Esta confianza en el progreso de los alumnos es visualizada por el rector de la institución como fundamental para poder trabajar con ellos. De acuerdo con su visión, la confianza equivale al deseo y a la convicción de que es posible lograr un cambio en sus condiciones de vida.

[...] en principio, me parece que si vos no querés a los pibes no podés estar en la escuela [...] Querer a un pibe es decir "Creo en él y quiero un destino diferente al que trae". [...] Yo insisto, si [...] no creés que la educación puede hacer algo por ese pibe [...] Yo creo que ahí está el tema [...] para mí la clave es que vos entrás a un aula con ganas de lograr algo en esos pibes [...] (Entrevista al rector de la institución). 
En la misma línea, los profesores de las asignaturas observadas también reflejan en sus discursos la confianza en las posibilidades de aprender de sus alumnos.

[...] En todos los grupos humanos hay pibes que tienen más interés en el tema, otros que tienen menos interés, tienen más interés en aprobar la materia y recibirse, y otros que tienen no tanto interés [...]. Entonces ahí se dan, se dan las diferencias, pero no por capacidades [...] Todos tienen las mismas capacidades [...] No es lo mismo un muchacho que tiene que salir a laburar [trabajar] al que no. Lo que no significa que el que tiene que salir a laburar tenga menos capacidad de... escritura [...] (Entrevista al profesor de la Asignatura 1).

[...] tienen... es un problema de autoestima [...] que ellos no pueden [...] A mí me llegaron a decir "A mí no me da la cabeza [no tengo capacidad] [...]". Y les digo "pero si [a] ustedes no les da la cabeza, no estarían acá en una escuela". Esto es una escuela normal, más allá de las dificultades del contexto en que se encuentran [...] Habría que romper esta cuestión de que "Yo no puedo" porque ellos están evidenciando eso. "Yo no puedo", “yo no debo" y sí que pueden. Yo estoy convencido de que pueden. [...] (Entrevista al profesor de la Asignatura 2).

[...] uno sabe qué pibe tiene más capacidad para poder estudiar y qué pibe vos le podés ajustar. Vos a Martu y a Ernes [alumnos de quinto año] los ajustás un poco más y son pibes que te rinden, tranquilamente. [...] Está más estereotipado que Ernes es un tipo que sabe, que entiende y que Lauti no. Y Lauti tiene esa carga encima. [...] Si uno desde afuera hace esta lectura de "Y... uno es mejorcito que el otro", por ahí él también tiene esa carga sobre su espalda. [...] (Entrevista a la profesora de la Asignatura 3).

En las citas transcriptas, el profesor de la Asignatura 1 hace hincapié en la igualdad de "capacidades" de sus alumnos, más allá de las diferencias de intereses o de situaciones de vida que reflejan. De modo similar, la docente de la Asignatura 3 destaca los rendimientos de sus alumnos y menciona que los estereotipos de los profesores ejercen una carga sobre algunos de ellos, lo que incide en sus desempeños. El profesor de la Asignatura 2 también enuncia su confianza en los estudiantes y marca la necesidad de explicitarla, ya que ha presenciado comentarios que revelaron su baja autoestima.

Además de que el discurso de estos profesores expresa la confianza en la capacidad de aprender de sus alumnos, nuestras observaciones de clase muestran que estos docentes expresan también su convicción en el trabajo áulico diario. De esta forma, esta confianza "hace acto" (Cornú, 1999: 21) y es capaz de ser percibida por los estudiantes, otorgándoles una cuota de seguridad en sí mismos, que puede incidir en su motivación por asistir a la escuela. En este punto, explicitar la confianza puede facilitar el logro de otro de los lineamientos expuestos en un documento de trabajo que recogimos en esta escuela: "promover en el adolescente en dificultades la necesaria confianza en sí mismo".

Seleccionamos los siguientes fragmentos de clase que lo evidencian:

- $\quad$ Extracto de clase $\mathbf{N}^{\circ}$ 1:

[Al comienzo, el docente de la Asignatura 1 realiza una extensa exposición oral sobre la deuda externa. Luego indica leer un pequeño texto de un manual escolar y contestar las preguntas que figuran en un cuestionario. A medida que finalizan la tarea, los estudiantes entregan sus hojas al docente. Hacia el final de la clase, sólo quedan escribiendo en el aula 
dos de ellas: Claudia y Yésica]

Claudia: [Entrega su hoja] No lo pienso arreglar si está mal.

Docente Asignatura 1 (D1): Bueno [Echa un vistazo a la producción de Claudia] ¿Y porqué tendría que estar mal? Si está bien.

Claudia: Por eso le digo, si estaba mal, no lo iba a arreglar.

D1: ¿Y porqué tenés que pensar que está mal?

Claudia: [No responde. Comienza a guardar sus útiles en la mochila]

\section{- $\quad$ Extracto de clase $\mathbf{N}^{\circ} 2$ :}

[El docente de la Asignatura 2 organiza la puesta en común de un cuestionario sobre la construcción socio-histórica de diversas juventudes]

Daiana: Yo lo terminé pero necesito que me lo explique porque no entiendo.

Docente Asignatura 2 (D2): [Se acerca y lee una de las respuestas de Daiana] Pero ustedes tienen que leer esto porque está muy bien [...] hay que animarse a leer lo que producen. Porque cuando ustedes van a seguir otra carrera... [...]

Yésica: ¿Usted piensa que vamos a salir de acá...?

Carla: $6 . . . y$ vamos a seguir una carrera?

D2: Yo creo que sí, chicos, yo creo que sí [...] ya están ustedes en la recta final [...] no hay que bajar los brazos [rendirse] [...] Tal vez se tengan que esforzar un poco más. [...]

[La clase continúa con otros intercambios verbales acerca de las carreras que los estudiantes dicen querer estudiar al finalizar la escuela secundaria]

\section{- $\quad$ Extracto de clase $\mathbf{N}^{\circ}$ 3:}

[El profesor de la Asignatura 2, preocupado por algunos comentarios negativos de los alumnos acerca de la enseñanza brindada por la escuela y de la posibilidad de continuar estudiando, había armado una encuesta con preguntas sobre sus sentimientos respecto a estos temas. En esta clase, expone oralmente un resumen de las respuestas de los estudiantes] D2: [...] yo como había visto tanto escepticismo en esta mirada negativa de lo que era la escuela y el futuro [...] les hago una devolución [Lee varios fragmentos textuales de las respuestas] Siempre hay que luchar y se puede, yo quiero decirles que se puede.

\section{- $\quad$ Extracto de clase $\mathbf{N}^{\circ}$ 4:}

[La docente de la Asignatura 3 indica a los alumnos dividirse en pequeños grupos para leer textos distintos sobre el tema de paraísos fiscales y luego socializar con el resto del curso lo entendido]

Fabiana: [Discute al interior de su grupo sobre los temas leídos] Lo legal es la plata que uno gana a través de un trabajo y lo ilegal cuando robas [...] venta de armas.

Carla: Bien.

Fabiana: [Percibe que la docente está atenta a sus conversaciones] iY encima estás escuchando vos! Así que ya estás sabiendo qué estamos hablando.

Docente Asignatura 3 (D3): Quiero saber cuál fue la explicación de legal e ilegal porque la de recién fue bastante [...] pobretona [insuficiente].

Fabiana: Bueno....

D3: [Dirigiéndose al grupo de chicas compuesto por Fabiana, Carla y Lorena] Yo tengo confianza en este grupete [grupo]

[Transcurrido el tiempo destinado para leer, dicho grupo comienza a exponer] 
Lorena: Eh... [Se detiene, mira el texto] los paraísos fiscales son estados o lugares eh... [Hace una larga pausa, relee el texto] que poseen regímenes fiscales...

D3: Tranqui, tranqui, ya va a aflojar, ya va a aflojar [ya va a salir la explicación]

Los extractos de clase transcriptos ilustran cómo, de diversas formas, los tres docentes explicitan su confianza en las posibilidades de aprender de sus alumnos. Lo hacen en momentos donde éstos dudan de sí mismos: “¿y porqué tendría que estar mal? Si está bien" (Extracto $\mathrm{N}^{\circ} 1$ ), "hay que animarse a leer lo que producen" (Extracto $\mathrm{N}^{\circ} 2$ ), "yo quiero decirles que se puede" (Extracto $\mathrm{N}^{\circ} 3$ ), o cuando entienden que deben alentarlos a seguir trabajando alguna idea conceptual inicialmente errónea: "yo tengo confianza en este grupete [...] tranqui, ya va a aflojar" (Extracto $\mathrm{N}^{\circ} 4$ ). Estas expresiones resultan alentadoras para estos jóvenes que, de acuerdo con sus comentarios en clase, desconfían de sus capacidades y de su futuro como estudiantes de niveles superiores.

En definitiva, los fragmentos de entrevistas y observaciones de clase muestran que, ante esta baja autoconfianza académica, los docentes fomentan un vínculo positivo y manifiestan confianza en sus posibilidades de aprender. Estas acciones tienen resonancia en estos alumnos cuyo historial escolar se caracteriza por reiterados "fracasos": saben que, en esta institución, cuentan con profesores que creen en ellos, dispuestos a acompañarlos y ayudarlos a finalizar su escolaridad secundaria.

\section{DISCUSIÓN}

En este artículo hemos descrito las diversas acciones de tipo institucional y vincular llevadas a cabo por los integrantes de esta institución. Dichas acciones se destacan, tanto en sus discursos y acciones, como favorecedoras de la permanencia escolar de los alumnos, de acuerdo con la bibliografía revisada.

La asunción por parte de los directivos y los docentes de un compromiso produce un fuerte involucramiento con los principios del proyecto educativo, y una correlativa suma de esfuerzos pedagógicos por el logro de los objetivos allí planteados. Abordar conjuntamente las problemáticas que puedan emerger y poner en riesgo la permanencia escolar de los alumnos forja un núcleo de personas dispuestas a analizar y aportar diversas soluciones. Simultáneamente, la búsqueda de la permanencia se potencia mediante el vínculo afectivo que se construye con los alumnos porque los motiva a asistir a clases. Los docentes declaran confiar en las posibilidades de aprender de los estudiantes, y así lo explicitan en las clases, lo que puede suscitar que los segundos desarrollen seguridad en sí mismos.

El comportamiento de los alumnos en la escuela no puede tratarse con la misma vara que en otros contextos socioculturales porque, si así se lo hiciera, se cometería una nueva injusticia con la población recibida, expulsándola por segunda vez de la integración social. Por ello, la consideración de las particularidades de estos alumnos mediante esta red de acciones constituye una toma de postura institucional (Cantero, 1999), que se fundamenta y se extiende a través de toda la práctica educativa. Quienes desarrollan estas acciones lo hacen desde una posición crítica a nivel político, que visualiza la situación social de los estudiantes como telón de fondo condicionante de los procesos de enseñanza. Sin embargo, parece necesario que esta comprensión no conlleve actitudes de resignación o impotencia, sino que habilite "lecturas en positivo" (Charlot, 2006: 36) acerca de las posibilidades 
de retener a los alumnos. Es decir, pensar las circunstancias de vida de estos alumnos no como obstáculos insalvables, sino como puntos de partida para diseñar intervenciones institucionales efectivas (Dabenigno et al., 2010). A través de evidencia empírica, este estudio muestra que dicha "lectura en positivo" es posible, y que siembra bases para asegurar el derecho a la educación de alumnos con estas características.

La permanencia escolar, entonces, aparece como condición inicial y necesaria que debe asegurarse para estos estudiantes, cuyas problemáticas socioeconómicas los llevan, a menudo, a interrumpir sus trayectorias escolares. No obstante, se trata sólo de un punto de partida, que no debe hacer perder de vista la función propiamente educativa de la escuela: favorecer la apropiación de saberes. Con los alumnos asistiendo a clase, luego, será necesario pensar cómo construir condiciones didácticas adecuadas para enseñar contenidos disciplinares.

\section{REFERENCIAS BIBLIOGRÁFICAS}

Acosta, F. (2009). Re-configuración de la escuela secundaria frente al ingreso masivo de jóvenes populares. Revista de Pedagogía, vol.30 (87), 217-246.

(2006). Escuelas medias y sectores populares: Entre la eficacia y la ley, la moral y la cultura. Revista Electrónica Iberoamericana sobre Calidad, Eficacia y Cambio en Educación, vol.4 (3), 16-29.

Bain, K. (2004). How Do They Treat their Students? What the Best College Teachers Do. Cambridge, MA: Harvard University Press.

Baquero, R. (2001). La educabilidad bajo sospecha. Cuadernos de Pedagogía, vol.4 (9), 71-85.

Belossi, M. A. y Palacios de Caprio, M. A. (1999). La escuela media y los jóvenes socialmente desfavorecidos. Buenos Aires: Lugar Editorial.

Bourdieu, P. y Saint Martin, M. (1998). Las categorías del discurso profesoral. Propuesta Educativa, vol.9 (19), 4-18.

Cantero, G. (1999). La gestión escolar en condiciones adversas. Síntesis de una investigación. Revista IRICE, (13), 31-54.

Carlino, P. (2005). Escribir, leer y aprender en la universidad. Una introducción a la alfabetización académica. Buenos Aires: Fondo de Cultura Económica.

Charlot, B. (2006). La relación con el saber. Elementos para una teoría. Montevideo: Trilce.

Coffey, A. \& Atkinson, P. (1996). Concepts and Coding. Making Sense of Qualitative Data. London: Sage.

Cornú, L. (1999). La confianza en las relaciones pedagógicas. En G. Frigerio, M. Poggi y D. Korinfeld (Comps.), Construyendo un saber sobre el interior de la escuela (pp. 19-26). Buenos Aires: Novedades Educativas.

Dabenigno, V., Larripa, S., Austral, R., Tissera, S. y Goldenstein Jalif, Y. (2010). Permanencia e involucramiento escolar de los estudiantes secundarios. Perspectivas y acciones en cuatro escuelas estatales de la Ciudad de Buenos Aires. Ciudad de Buenos Aires: Dirección de Investigación y Estadística, Ministerio de Educación. Recuperado el 4 de marzo de 2013 desde http://www. buenosaires.gob.ar/areas/educacion/dirinv/pdf/permanenciainvolucramientosecundarios2010.pdf

Falconi, O. (2011). La experiencia escolar de alumnas y alumnos de sectores pauperizados en instituciones públicas. El Monitor de la Educación, (28), 24-37.

Feijoo, M. C. y Corbetta, S. (2004). Escuelas y pobreza. Desafios educativos en dos escenarios del Gran Buenos Aires. Buenos Aires: IIPE-UNESCO.

Fernández, L. M. (1994). Instituciones educativas. Dinámicas institucionales en situaciones críticas. Buenos Aires: Paidós.

Foglino, A. M., Falconi, O. y López Molina, E. (2008). Una aproximación a la construcción de la 
experiencia escolar de adolescentes y jóvenes de grupos sociales urbanos en condiciones de pobreza en Córdoba. Cuadernos de Educación, vol.6 (6), 227-243.

Fredricks, J. A., Blumenfeld, P. C. \& Paris, A. H. (2004). School Engagement: Potential of the Concept, State of Evidence. Review of Educational Research, vol. 74 (1), 59-109.

Frigerio, G. (2004). La (no) inexorable desigualdad. Ciudadanos, vol. 4 (7/8), 35-41.

Jacinto, C. y Terigi, F. (2007). ¿Qué hacer ante las desigualdades en la educación secundaria? Aportes de la experiencia latinoamericana. Buenos Aires: Santillana.

y Freytes Frey, A. (2004). Políticas y estrategias para el mejoramiento de las oportunidades de los jóvenes: Estudio sobre la educación secundaria en la Ciudad de Buenos Aires. París: UNESCO-IIEP.

Kaplan, C. (2010). La confianza hacia las posibilidades de aprender de los alumnos: Un umbral necesario para abordar la diversidad sociocultural en la escuela. En M. Vergara Fragoso y J. A. Ríos Gil (Coords.), Diversidad cultural: Un reto para las instituciones educativas (pp. 81-100). Guadalajara: Universidad de Guadalajara.

(2005). Subjetividad y educación ¿Quiénes son los adolescentes y jóvenes, hoy? En

M. Krichesky (Comp.), Adolescentes e inclusión educativa. Un derecho en cuestión (pp. 97-112). Buenos Aires: Noveduc.

Kessler, G. (2002). La experiencia escolar fragmentada. Estudiantes y docentes en la escuela media en Buenos Aires. Buenos Aires: IIPE-UNESCO.

Krichesky, G. y Duque, J. (2008). Las prácticas inclusivas en la escuela media: La perspectiva de los jóvenes. Buenos Aires: Cimientos-Fundación para la Igualdad de Oportunidades Educativas.

., Migliavacca, A., Alcántara, A., Glass, A., Cabado, G., Greco, M. y Medela, P. (2008).

Escuelas medias en contextos de vulnerabilidad social. Perspectivas sobre gestión institucional y políticas de inclusión educativa en la Ciudad de Buenos Aires. Buenos Aires: Dirección de Investigación y Estadística. Recuperado el 13 de abril de 2013 desde http://estatico.buenosaires.gov. ar/areas/educacion/dirinv/pdf/esc_medias_vulnerabilidad_social_08.pdf

López, N. (2006). Educación y desigualdad social. Buenos Aires: Ministerio de Educación, Ciencia y Tecnología de la Nación.

Maxwell, J. A. \& Miller, B. A. (2008). Categorizing and Connecting Strategies in Qualitative Data Analysis. In S. N. Hesse-Biber \& P. Leavy (Eds.), Handbook of Emergent Methods (pp. 461477). New York: Guilford Press.

Poggi, M. (2003). La problemática del conocimiento en la escuela secundaria: Algunas perspectivas sobre el abordaje de los aspectos curriculares. En E. Tenti Fanfani (Comp.), Educación media para todos. Los desafíos de la democratización del acceso (pp. 105-137). Buenos Aires: UNESCO-IIPE.

Redondo, P. (2004). Escuelas y pobreza. Entre el desasosiego y la obstinación. Buenos Aires: Paidós.

Rosenthal, R. \& Jacobson, L. (1968). Pygmalion in the Classroom: Teacher Expectation and Pupil's Intellectual Development. New York: Holt, Rinehart \& Winston.

Stake, R. E. (2000). Case Studies. In N. K. Denzin \& Y. S. Lincoln (Eds.), Handbook of Qualitative Research. $2^{\text {nd }}$ Edition (pp. 435-454). Thousand Oaks, CA: Sage.

Thisted, S. (2011). Escuelas en la trama de las desigualdades y las diferencias culturales. Debates y aportes para pensar la educación intercultural. En N. Elichiry (Comp.), Políticas y prácticas frente a la desigualdad educativa. Tensiones entre focalización y universalización (pp. 43-58). Buenos Aires: Noveduc.

Tiramonti, G., Arroyo, M., Nobile, M., Montes, N., Poliak, N., Sendón, M. A. y Ziegler, S. (2007). Nuevos formatos escolares para promover la inclusión educativa. Un estudio de caso: La experiencia argentina. Informe final. Buenos Aires: FLACSO. Recuperado el 6 de septiembre de 2013 desde http://educacion.flacso.org.ar/files/proyectos/pdf/informe_formatos_escolares.pdf

UNESCO/IIPE (2000). Los docentes argentinos. Resultados de una encuesta nacional sobre la 
Estudios Pedagógicos XLI, N 1: 257-274, 2015

ACCIONES INSTITUCIONALES Y VINCULARES QUE FAVORECEN LA PERMANENCIA ESCOLAR DE ALUMNOS DE SECTORES SOCIOECONÓMICOS DESFAVORECIDOS

situación y cultura de los docentes. Recuperado el 12 de septiembre de 2013 desde http://www.iipebuenosaires.org.ar/system/files/documentos/los_docentes.pdf

Ziegler, S. (2011). Entre la desregulación y el tutelaje: ¿Hacia dónde van los cambios en los formatos escolares? En G. Tiramonti (Dir.), Variaciones sobre la forma escolar. Límites y posibilidades de la escuela media (pp. 71-88). Buenos Aires: Homo Sapiens. 